Chapter 2

\title{
Developing a Background for Forest Adaptation Strategies in the Alps: A Perspective for Policy Building
}

\author{
Luca Cetara and Federico Mannoni \\ Additional information is available at the end of the chapter \\ http://dx.doi.org/10.5772/56274
}

\section{Introduction}

Over the last two decades, since the Rio de Janeiro's UN Conference on Environment and Development (UNCED) in 1992, a growing demand for policy making in the forest sector has emerged at the global level in connection to the challenge of climate change.

The UN-declared 2011 "International Year of Forests" ended with some important steps forward achieved at the Durban's 17th Conference of the Parties of the United Nations Framework Convention on Climate Change [Perugini et al., 2012].

Meanwhile, the evolution of this process has progressively resulted in an articulated international regulatory framework based on a plurality of agreements and policy initiatives coping with the complex issue of protecting the forest ecosystems and managing them in accordance to the principles of sustainability.

Historically, among the landmark steps in the development of regulatory principles and schemes addressing the forest sector and recognizing the inner multi-functionality of forest ecosystems in the international environmental law, it is worth mentioning, for instance, the Convention on Biological Diversity (CBD), that dedicates a detailed work programme to protect the biodiversity stored in forests, and the United Nations Convention to Combat Desertification (UNCCD), that recognizes the relevance of the role of forests in fighting the process of desertification connected with global warming [EUROPEAN COMMISSION, 2010].

In any case, as far as international schemes are concerned, and given the intrinsic transboundary dimension of the multiple, interconnected ecological, economic and social functions performed by forests as well as of the potential effects of climate change dynamics on them, the implementation of rational policy making in the sector requires forms of supranational endorsement flexible enough to facilitate sustainable forest management decisions 
that can be suitable to the different characteristics and conditions of the various forest sites existing on the Earth.

At the European level, Sustainable Forest Management (SFM) was adopted by the EU and its Member States as the central approach to forestry since 1993, with the adoption of Helsinki Resolution 1 the Ministerial Conference on the Protection of Forests in Europe.

Since then, European institutions refer to SFM as "the stewardship and use of forest lands in a way, and at a rate, that maintains their biodiversity, productivity, regeneration capacity, vitality and their potential to fulfill, now and in the future, relevant ecological, economic and social functions, at local, national and global levels, and that does not cause damage to other ecosystems" [MCPFE, 1993].

As the policy principles are defined, when aiming at implementing evidence-based sustainable forest management, taking account of the potential trade-offs and mutual benefits among the functions of mitigation and adaptation to climate change, as well as between the many other forest functions, becomes a crucial task to be undertaken [Spittlehouse and Stewart, 2003, FOREST EUROPE 2011].

Though, since the UNFCCC recognized the role of forests in the balance of global greenhouse gas emissions, a broader emphasis was traditionally put on their potential for climate change mitigation, either by reducing emission as a source for potentially wood-based renewable energy and as a sink for carbon sequestration [Guariguata et al., 2008, Campbell et al., 2009, FOREST EUROPE 2011].

It is nevertheless since 1990s that evidence for Europe continues to show that, according to current climate scenarios, forest ecosystems in this part of the world are expected to be particularly vulnerable to varying climate conditions.

In this context, the adaptation of the European forest sector to climate change represents a priority for ensuring that the provision of goods and services from forests can be maintained [Lindner, M. Kolström 2008, FAO 2011].

However, the development of adaptation measures is bound to a number of challenges to be dealt with in a context of scientific uncertainty. On the one hand, there is yet limited knowledge about the vulnerability of ecosystems and species as well as climate change impacts on the functional characteristics of forests in different bio-climatic zones (inherent adaptive capacity). On the other, adaptation measures also depends on a range of socio-economic conditions, whose future adjustments are uncertain [Burton et al., 2002, Spittlehouse and Stewart, 2003, Lindner, Kolström, 2008].

\section{EU and Alpine legal framework for mitigation and adaptation in the forest sector}

At the EU level, work is in progress and actions have been proposed to support and enhance sustainable forest management and the role of forest multi-functionality in the contribution to the Lisbon EU 2020 Strategy and the Gothenburg Agenda on sustainable development. 
Remarkably forerunning to the processes at stake, the EU Forest Action Plan [European Commission, 2006], building on the Council Resolution of 15 December 1998 on a forestry strategy for the European Union, have identified four main guiding objectives commonly on which to ground the implementation of a coordinated forest policy by the EU and Member States that need to be address the concepts of multi-functionality and sustainable forest management:

i. improving long-term competitiveness;

ii. improving and protecting environment;

iii. $\quad$ contributing to quality of life;

iv. fostering communication and coordination

More specifically, in order to implement these objectives, the Action Plan outlines eighteen Key Actions.

All these actions, in view of their intrinsic interrelation, have a relevance to be taken into account when devising adaptation strategies in the forest sector. Some of them, however, together with the measures outlined for their practical implementation, can be intrinsically seen as directly referable to policy-building for adaptation to climate change:

- the support of research and studies on climate change impacts and adaptation measures (Key Action 6);

- the enhancement of EU forests protection from biotic and abiotic hazards also by encouraging cooperation between Member States to study particular regional problems with the condition of forests (Key Action 9);

- maintain and enhance the protective functions of forests against the increasing threats of natural disasters and extreme events also through coordinated monitoring and planning, awareness raising and knowledge transfer on natural hazard and risk management, with a focus on mountain areas (Key Action 11)

A report on the state of the art of its implementation of the EU Forest Action Plan 2007 - 2011 will be presented to the Council and the European Parliament during 2012, in order to evaluate potential further developments.

Relevant to the analytic scope of the present paper, the EU Forest Action Plan has aimed at mainstreaming adaptation of European forests to climate change as a clear policy objective in a context where, in compliance with the subsidiarity principle, competence in forest policy lies primarily with the Member States. The role of the EU in forest policy, in fact, technically applies according to the principle of vertical subsidiarity (art. 5 of the EU Treaty), consequently meaning that the EU competencies are expected to simply perform in those cases where action by Member States is not sufficient and can be better achieved at the Union level.

With regard to forest policies, in particular, the EU role was historically limited to monitor and report on the state of EU forests; anticipating and stimulating attention of Member States on 
emerging global challenges and trends; proposing and coordinating or supporting early action at the EU level.

Moving in this complex, multi-dimensional institutional framework, innovative policy approaches have to be conceived to address the challenges posed by the need to ensure sustainability and adaptation of those forest resources that, due to their peculiar vulnerability and trans-boundary relevance, require apt regional policy-making strategies.

Not for a case, it has been recently affirmed by the FAO [2011] that there is a need for measures to protect mountain forests to be based on enhanced coordination at international and national levels, in consideration of local specificities and by integrating forest issues into broader policies and programmes.

Here, we focus on the Alpine forests and their specific functions, with the aim of analyzing a potential action framework for an effective and evidence-based policy building that can devise adaptive forest management strategies suitable to the peculiar adaptation needs of the area, representing at the same time an integrated element of the guiding measures and principles set out at the multiple level of decision making (EU, Alpine, national, local) co-existing in a multinational model of governance and cooperation.

Alpine forests retain the characteristics to represent an important pilot area for implementing adaptive strategies under consideration here, for a range of institutional, ecological and socioeconomic reasons.

Under an institutional perspective, the Alpine Convention, quite peculiarly in international environmental law with regard to this sector, provides a regulatory framework for implementation of transboundary cooperation in sustainable forest management: the Alpine Convention was in fact the first framework agreement at the level of international law on the protection and sustainable development of a transboundary mountain region.

More precisely, the Alpine Convention is an international treaty between the Alpine countries (Austria, France, Germany, Italy, Liechtenstein, Monaco, Slovenia and Switzerland) as well as the EU open to signature in Salzburg (Austria) on 7 November 1991, aimed at promoting sustainable development in the Alpine area and at protecting the interests of the people living within it, embracing the environmental, social, economic and cultural dimensions.

In any case, as commonly designed within the international environmental law due to the technical and scientific complexity of the provisions' contents, the implementation of the general principles of the framework agreement is to be further delegated to the Protocols [Munari, 2006].

For implementing the Alpine Convention's goals for the forest sector, since 1996, the "Mountain Forests" Protocol - done at Brdo (Slovenia) on 27th February of that year - identifies a set of specific functions of Alpine mountain forests whose conservation and enhancement is to be considered as a priority in the overall regional sustainable development policy.

By the attribution of a legal status to these functions, the Contracting Parties have therefore designed a platform for international cooperation (art. 4) at multiple levels of decision-making 
(art. 3) to pursue the preservation and improvement of forest assets even in a cross-sectoral perspective with other policy fields, also by means of cooperation in research, education and information (Chapter III).

Particularly relevant in a perspective of climate change adaptation, the "Mountain Forest" Protocol highlights the relevance of the protective function (art. 6), the economic function (art. 7 ), and of the functions of social and ecological character such as, among the others, water resources, clean air, biodiversity and recreation (art. 9).

\section{Major impacts of climate change on Alpine forests and their functions}

Climate change is expected to determine major ecological, social and economic effects on Alpine forests: as a result of the combined effects of land abandonment and decrease of limiting tree growth factors at higher altitudes because of higher temperatures, the process of forest cover expansion in the Alps - currently around 7.5 million ha, the $43 \%$ of the total Alpine land surface [EEA, 2009] - which is ongoing in the last decades is expected to continue, probably at higher rates.

Climate change may also affect tree growth patterns and species distribution, as well as increase the spread and intensity of, respectively, abiotic (fires, storms, drought, precipitations, atmospheric pollution) and biotic (pests and diseases) disturbances. These climate change impacts may therefore trigger plural interdependent effects that could alter a range of socially and economically critical Alpine-specific forest functions.

Nevertheless, knowledge still lacks on the magnitude and trends of these impacts and on how they may affect, positively or negatively, the livelihood of highland and lowland communities in a socio-economic perspective [IPCC, 2007, Lindner, Kolström et al. 2008, FAO, 2011].

In this line, the mentioned research outcomes, policy making guidelines and experience in Alpine forest adaptive management have suggested to place a particular focus on:

- the protective function for human infrastructures from natural hazards like flooding, debris flows, landslides, avalanches and rockfalls, is one of the most important function played by mountain forests: for instance, $20 \%$ of Austria's forests is considered as having a protective role, meanwhile $63 \%$ of Bavarian forests are declared as having a protective function against soil erosion and $43 \%$ against avalanches, in Germany. Concerning the economic and social value related to mountain forests' protective function in Alpine territories, a telling example comes from the Swiss Alps where it has been estimated that, in their absence, the cost of ensuring protection against avalanches using permanent ad hoc defense structures would be around some 89 billion Euros, 5-20 times more than that of maintaining healthy protection forests [FAO, 2011]. However, protection forests are sensitive to varying climate dynamic, even though it is difficult to assess the complexity of interaction, as it depends on many structural and compositional properties. In theory, diverse species composition, sufficient natural regeneration and an optimal structure favour the forests' protective function. As climate change could significantly 
alter the plant's phenology, physiology and distribution, strategies have to be implemented in the Alps to deal with the potentially increased silvicultural challenges already at play - poor regeneration, low proportion of medium-aged trees, exposure to intensified natural disturbances [Lindner, Kolström et al., 2008, FAO, 2011]. In this regard, some significant actions have already been undertaken at the pan-alpine level. In particular, the MANFRED Project "Management Strategies to adapt Alpine Space forests to climate change risks", launched in the context of the European Territorial Cooperation Alpine Space Programme 2007 - 2013 has developed a framework to undertake cooperative action in research and policy-making with regard to assessing the impacts of climate change on forests all over the Alpine arc, with a special focus on the interrelation among climate change scenarios and biotic and abiotic hazard factors dynamics. The expected results goes precisely in the direction of improving knowledge-based transnational cooperation and experience sharing in forest adaptive management at the Alpine level in order to address, among the others, the capacity of forests in the Alps of enduring their protective function also in a context of varied climatic conditions.

- The productive function of wood and non-wood forest goods and services may be consistently altered by climate change with both a) potential pros and cons as well as with $b$ ) trade-offs between the different potential economic uses of the same forest parcel. In the first case, for instance, wood productivity is expected to increase at higher elevations as a consequence of climatic changes as far as the water supply is sufficient, meanwhile at lower elevations changes species competition and adaptive capacity to natural disturbances may lead to decreasing productivity, also affecting the economic profitability patterns and their differences existing between highland and lowland forestry [Lindner, Kolström et al., 2008, FAO, 2011]. Instead, referring to different potential forested land uses, by the way of example, trade-offs exist between use of forest as carbon sinks or for biomass production, which are determined by both socio-economic conditions such as market prices and demand for biomass energy from forests as well as climate change-related effects [Lindner, Kolström et al., 2008]. In fact, studies suggest that the Alps are expected to maintain their carbon sink capacity at least for the first half of the 21st century, while increasing respiration rates and natural disturbances at low elevation sites may decrease thus making Alpine forests a carbon source [Karjalainen et al., 2002, Thürig et al., 2005, Zierl and Bugmann, 2007].

- The social and economic functions of forests include other forest services such as biodiversity, fresh and clean air water supply, or landscape that are finally relevant for the provision of other cultural and tourist-related economic ecosystem services potentially bearing sitespecific positive externalities. The value of these positive externalities is often not disclosed on markets as they are generally public goods, but their importance is crucial for the livelihood of communities inside and outside the mountain regions [TEEB, 2010; FAO, 2011]. Hence, their assessment is fundamental for the implementation of rational public choices in forest management adaptation planning. 


\section{Adaptation strategies for the Alpine forest sector}

The Alpine region as a whole can be considered as a particularly vulnerable area to the impacts of climate change, both physically and socially, with a clear need to build resilience through improved adaptation capacity. A strong need for adaptation has emerged from several scientific and policy-oriented sources (including the Climate Action Plan adopted by the Alpine Convention in Evian, 2009), experiences conducted in the Alpine countries and in other literature (EEA 2009, OECD 2007). In particular the necessity to focus and undertake cooperative research on the adaptation side of mountain forests in the Alps has been increasingly recognized as a central strategic topic in the framework of the Territorial Cooperation goals of the "Alpine Space Programme". As recalled above, the MANFRED Project, for example, directly addresses the topic of adaptation in Alpine forests to the impacts of climate change. In short, the project was focused on the assessment of potential future climate and land use dynamics' patterns, on the related impacts of them on abiotic and biotic hazard factors, on the historical frequency of and statistics on extreme events and related management practices in the Alpine forests, and on the sharing of knowledge about protection forests engineering in the Alps. All these fields of activity are expected to contribute to the definition of shared guidelines for sustainable forest adaptive management at the Alpine level, also based on the direct involvement of relevant stakeholders and the sound consideration of their preferences during the multiple stages of the project implementation.

Some forest-based adaptation activities have been recently identified as including monitoring and maintaining forest health, vitality and diversity; implementing integrated forest fire management; enhancing landscape connectivity and reducing forest fragmentation; monitoring and removing invasive species and addressing pest and disease threats; implementing reduced-impact logging; selecting appropriate species for use in planted forests; undertaking forest restoration and rehabilitation, particularly on slopes, through specific measures and tools that can facilitate the adaptation process [Ciccarese et al. 2012].

However, the concrete design and implementation of climate change adaptive strategies as part of sustainable forest management requires making policy choices between sets of different adaptation options often implying potential co-benefits and trade-offs between environmental, social and economic functions [Spittlehouse and Stewart, 2003, FOREST EUROPE 2011].

Moreover, choices between adaptation measures have to be taken in a long-term perspective - as the long life-span and growing conditions of trees does not allow for rapid adaptation to environmental change in a context of temperature increase in the Alps over the last century that is already twice the global average (about $1.5^{\circ} \mathrm{C}$ ), with a slightly growing tendency at higher altitudes [Houghton et al., 2001, Casty et al., 2005, IPCC, 2007]

Nevertheless, there is still a high degree of scientific uncertainty about regional future climate conditions and how they will impact on forests health and growing patterns [Roetzer, 2005; IPCC, 2007, Lindner, Kolström 2008]. For forest sector policy-making to be effective, reliable information has to be available: collaborative, interdisciplinary research has to be further developed in order to provide policy-makers and relevant stakeholders inside and outside the 
forest sector with the necessary evidence-based tool for rational decision-making [FOREST EUROPE 2011, FAO 2011]. Furthermore, research demonstrated the ability to develop sensible decision support systems for different sectors, that can be applied in different regions (some examples for the Alps: Climalptour, SHARE, etc.).

\section{Policy framework and perspectives for policy building}

The actual use of forests can be socially and historically rooted in each considered area [Agnoletti and Anderson a) and b), 2000, Williams, 2006]. Different forest uses and policies can bring different contributions to regional economic development trends, by producing variable degrees of income and wealth from forest marketed and non-marketed services [FOREST EUROPE 2011].

The historical persistence of some forest uses observed locally and the priorities set by policy makers at different levels (e.g. increasing wood supply and mobilization are common to several European, Alpine and non-Alpine regions' forest policy) suggest to assign different relative weights to the contribution that each forest function supplies to the economy and society in different countries and sub-regions.

In turn, this discretionary and site-specific weighting is likely to impact on the actual mix of adaptation measures that regional governments will support, incentivize and implement.

Thus, when selecting sector-specific adaptation measures, decision makers are called to inspect:

- the physical and ecological features of the region that participate in determining its inherent adaptive capacity [Lindner and Kolström 2008, EEA 2009],

- the composition and historical roots of the regional economy - where some economic indicators for the profitability of forestry have been calculated for EU forests [Kovalcik 2011],

- the priorities set (or to be set) at different political levels in the region under inquiry [Lindner and Kolström 2008].

From this situation, a few guiding principles for the definition of suitable adaptation policies can be extracted:

- climate change impacts on the forest functions can assume a variable social and economic weight, on the basis of some situational variables, which may include the structure of the economy, the forest sector contribution to regional GDP, the regional labor market structure, the social consequences of policies and trends observed in the forest sector, the functions and services provided by forest ecosystems, and their formal understanding from the scientific community;

- public awareness existing on climate change impacts at the local level is a key factor to be taken into account when defining adaptation policies. In particular the perceptions of policy makers, of the scientific community, of qualified stakeholders and of the general public on 
the relative weights and role of the climate change-affected forest functions at the regional level should be attributed a specific policy focus. Namely, particularly relevant is the dissemination of the available information to user groups and forest owners [Lindner and Kolström 2008, FAO 2011];

- considerations on, and choices about trade-offs and co-benefits eventually deriving from adaptation measures in the forest sector are likely to be context-specific, i.e. dependent on the framework conditions observed in the region at the economic, social, ecological and policy-level.

Current figures reveal that in Europe the average share of forestry in the GDP is modest and corresponds on average to $0,31 \%$, with slightly higher values in Austria and Slovenia. [FOREST EUROPE 2011]. At the same time, entrepreneurial income per hectare shows very variable values across EU [Kovalcik, 2011].

In such a context, the regions where forestry and forest policies have only marginally developed, as it is the case also with some Alpine countries, phenomena of policy change and "paradigm shift" towards a comprehensive adaptation strategy to climate change and a concomitant sustainable forest management may be triggered only by a composite set of factors.

Among them, the following can be recalled: the results of scientific research, the increased understanding of the physical mechanisms behind forest functions, the novel knowledge available on the possible ecological, economic and social impacts of climate change, and the growth opportunities for the forest sector which have been identified at the economic and policy-analysis level, also in the framework of the 2012 United Nations Conference on Sustainable Development (UNCSD) in Rio de Janeiro, that explicitly addressed the theme of "Green economy in the context of sustainable development and poverty eradication [OECD 2011, UNEP 2011, UNECE 2012]. Conversely, the process of change in Alpine forest management may be hindered by the persistence of a high degree of regional vulnerability.

\section{Conclusions}

Building resilience to climate change in the Alpine forest sector by implementing suitable adaptation policies can therefore facilitate the sector's innovation and change. The process of policy change in addressing the challenges of the forest sector can be read as the consequence of an iterative feedback impacting on the framework conditions of the sector and the regional economy at large. This may stimulate a learning process consisting in information feedbacks being able to revise the behavioral model of decision making [Sterman, 1994], and potentially inducing increasing modifications in forest management.

In conclusion, such a feedback effect can be supported by several factors and conditions, that participate in determining the intensity and potential for change of the forest policies, including: 
- the presence (or absence) of already openly defined policy goals (policy stability of the forest sector);

- the existing stakeholders' claims and expectations;

- the expected impacts of climate change on the regional economy and society, and their relative weights;

- the resilience of Alpine forests to climate change and their actual and potential contribution to societal adaptation [Innes et al., 2009];

- the possible social and economic benefits that can derive from a more efficient forest management and target-oriented expenditure (e.g. reflecting in higher entrepreneurial revenues and employment levels, differently from the present situation) [FOREST EUROPE, 2011];

- the resulting attractiveness (in terms of expected economic, ecological and societal benefits) of the "paradigm shift" itself for key regional stakeholders and policy makers.

\section{Author details}

Luca Cetara $^{1}$ and Federico Mannoni ${ }^{2}$

1 Accademia Europea di Bolzano, Bolzano, Italy

2 Istituto per le Piante da Legno e l'Ambiente - IPLA, Torino, Italy

\section{References}

[1] Agnoletti, M, \& Anderson, S. eds.). Forest History: International Studies on Socioeconomic and Forest Ecosystem Change. In: IUFRO Research Series \#2. New York, NY: CABI Publishing. (2000a). , 418.

[2] Agnoletti, M, \& Anderson, S. eds.). Methods and Approaches in Forest History. In: IUFRO Research Series \#3. New York, NY: CABI Publishing. (2000b). , 281.

[3] Alpine ConventionProtocol on the Implementation of the Alpine Convention relating to Mountain Forests: "Mountain Forest" Protocol. (1996). http://www.alpenkonvention.org/en/convention/protocols/Documents/protokoll_bergwaldGB.pdfaccessed 02 May 2012)

[4] Alpine ConventionAction Plan on Climate Change in the Alps: AC_X_B6_fr. ; 2009 http://www.alpconv.org/en/ClimatePortal/actionplan/Documents/

AC_X_B6_en_new_fin.pdfaccessed 24 April (2012). 
[5] Brang, P, Schönenberg, W, Frehner, M, Schwitter, R, Thormann, J, \& Wasser, B. Management of protection forests in the European Alps: an overview. Forest, Snow and Landscape Research (2006).

[6] Burton, I, Huq, S, Lim, B, Pilifosova, O, \& Schipper, E. L. From impacts assessment to adaptation priorities: the shaping of adaptation policy. Climate Policy (2002).

[7] Campbell, A, Kapos, V, Scharlemann, J. P. C, et al. Review of the literature on the links between biodiversity and climate change: impacts, adaptation and mitigation, Secretariat of the Convention on Biological Diversity. Montreal: Technical Series n. $124 ;(2009)$.

[8] Casty, C, Wanner, H, Luterbacher, J, Esper, J, \& Böhm, R. Temperature and Precipitation Variability in the European Alps Since 1500. International Journal of Climatology (2005). , 1855-1880.

[9] Ciccarese, L, Mattsson, A, \& Pettenella, D. Ecosystem services from forest restoration: thinking ahead. New Forests International Journal on the Biology, Biotechnology, and Management of Afforestation and Reforestation 2012. http:// www.scribd.com/doc/54145282/European-Forestsaccessed 3 June (2012).

[10] European CommissionGreen Paper on Forest Protection and Information in the EU: Preparing forests for climate change. COM ((2010). final.

[11] European CommissionCommunication from the Commission to the Council and the European Parliament on an EU Forest Action Plan. COM((2006).

[12] European Environment AgencyRegional climate change and adaptation. The Alps facing the challenge of changing water resources. Copenhagen: EEA Report (2009). and 51-53.(8), 18-19.

[13] FAOThe state of the world's forests report, Rome: FAO; (2011).

[14] FOREST EUROPEUNECE, FAO. State of Europe's forests (2011). status and trends in sustainable forest management in Europe: conference proceedings. 14.16 June. 2011, Oslo, Ministerial Conference on the Protection of Forests in Europe (FOREST EUROPE)

[15] Guariguata, M. R, Cornelius, J. P, Locatelli, B, Forner, C, \& Sanchez-azofeifa, G. Mitigation needs adaption: Tropical Forestry and climate change. Mitigating Adaptive Strategies for Global Change (2008).

[16] Hemmati, M. Multi-Stakeholder Processes for Governance and Sustainability, Beyond Deadlock and Conflict, London: Earthscan; (2002).

[17] Houghton, J. T, Ding, Y, Griggs, D. J, Noguer, M, Van Der Linden, P. J, Dai, X, Maskell, K, \& Johnson, C. A. Climate change 2001: The scientific basis. Cambridge: Cambridge University Press; 2001. http://www.grida.no/climate/ipcc_tar/wg1/ index.htmaccessed 18 May (2012). 
[18] Innes, J, Joyce, L, Kellomaki, M, et al. Management for adaptation. In: Seppäla R., Buck A., Katila P. (eds). Adaptation of forests and people to climate change. Vienna: International Union of Forest Research Organizations IUFRO world series: (2009). , 135-169.

[19] IPCC- Intergovernmental Panel on Climate ChangeSummary for Policymakers.. In: Parry M.L., Canziani O.F., Palutikof J.P., van der Linden P.J. and Hanson C.E. (Eds.). Climate Change 2007. Contribution of Working Group II to the Fourth Assessment Report of the Intergovernmental Panel on Climate Change. Impacts, Adaptation and Vulnerability. Cambridge: Cambridge University Press; (2007). , 7-22.

[20] IPCC- Intergovernmental Panel on Climate ChangeWorking Group II Report: Impacts, adaptation and vulnerability: food, fibre and forest products. Cambridge: University Press; (2007).

[21] Karjalainen, T, Pussinen, A, Liski, J, Nabuurs, G. J, Erhard, M, Eggers, T, Sonntag, M, \& Mohren, G. M. J. An approach towards an estimate of the impact of forest management and climate change on the European forest sector carbon budget: Germany as a case study. Forest Ecology and Management: (2002). , 87-103.

[22] Kovalcic, M. Profitability and competitiveness of forestry in European countries. Journal of Forest Science (2011). , 369-376.

[23] Lindner, M, \& Kolström, M. Impacts of climate change in European forests and options for adaptation, Report to the European Commission Directorate-General for agriculture and Rural Development; 2008. http://ec.europa.eu/agriculture/analysis/ external/euro_forests/full_report_en.pdfaccessed 3 March (2012).

[24] Munari, F. Tutela Internazionale dell'Ambiente. In: Carbone S.M., Luzzato R. Santa Maria L. Istituzioni di Diritto Internazionale. Torino: Giappichelli; (2006). , 406-445.

[25] OECDTowards Green Growth. Paris: (2011). http://www.oecd.org/dataoecd/ 37/34/48224539.pdfaccessed 26 February 2012).

[26] Perugini, L, Vespertino, D, \& Valentini, R. Conferenza di Durban sul clima: nuove prospettive per il mondo forestale. Forest@ 2012; http://www.sisef.it/forest@/ contents/?id=688accessed 5 April (2012). , 9(1), 1-7.

[27] Price, M. F, et al. Mountain Forests in a Changing World- Realizing Values, addressing challenges. Rome: FAO/MPS and SDC; (2011).

[28] Roetzer, T. Climate change, stand structure and the growth of forest stands. Annalen der Meteorologie (2005). , 40-43.

[29] Somlai, I. G. Identifying stakeholders: Approach to Social Forestry Conflicts. International Journal of Social Forestry (2008). , 83-95.

[30] Spittlehouse, D. L, \& Stewart, R. B. Adaptation to climate change in forest management. BC Journal of Ecosystems and Management (2003). , 1-11. 
[31] Sterman, J. D. Learning in and about complex systems. System Dynamics Review (1994). , 291-330.

[32] TEEBThe Economics of Ecosystems and Biodiversity: Mainstreaming the Economics of Nature: A synthesis of the approach, conclusions and recommendations of TEEB, 2010. http://www.teebweb.org/Portals/25/TEEB\%20Synthesis/TEEB_SynthReport_09_2010_online.pdfaccessed 15 April (2012).

[33] Thuerig, E, Palosuo, T, Bucher, J, \& Kaufmann, E. The impact of windthrow on carbon sequestration in Switzerland: a model-based assessment. Forest Ecology and Management (2005). , 337-350.

[34] UNCEDReport of the United Nations Conference on Environment and Development 1992: Conference proceedings, June Rio de Janeiro, Annex III, 2b. http://www.un.org/ documents/ga/conf151/aconf15126-3annex3.htmaccessed 20 April (2012). , 3-14.

[35] UNEPTowards a Green Economy: Pathways to Sustainable Development and Poverty Eradication. Nairobi: United Nations Environment Programme; 2011. www.unep.org/greeneconomyaccessed 15 April (2012).

[36] Williams, M. Deforesting the Earth: From Prehistory to Global Crisis, An Abridgment. Chicago: University of Chicago Press; (2006). p xviii and 543.

[37] Zierl, B, \& Bugmann, H. Sensitivity of carbon cycling in the European Alps to changes of climate and land cover. Climatic Change (2007). , 195-212. 
